\title{
Atmospheric phenomena deduced from radiosonde and GPS occultation measurements for various application related studies
}

\author{
C J JohnY ${ }^{1, *}$, S K SARKAR ${ }^{1, * *}$ and D Punyasesudu ${ }^{2, \dagger}$ \\ ${ }^{1}$ Radio $\&$ Atmospheric Sciences Division, National Physical Laboratory, \\ Dr. K S Krishnan Marg, New Delhi 110 012, India. \\ ${ }^{2}$ Department of Physics, Post Graduate Study Centre, Sri Krishnadevaraya University, \\ Kurnool 518 002, A.P., India. \\ *e-mail: johnycj@rediffmail.com \\ **e-mail: sksarkar@mail.nplindia.ernet.in \\ ${ }^{\dagger}$ e-mail: dupadu@rediffmail.com
}

The tropopause height and tropopause temperature are sensitive to temperature changes in troposphere and stratosphere. These are the measures of global climatic variability. Atmospheric profiles of temperature, refractivity and water vapour are always needed for communication, navigation and atmospheric modeling studies. The tropopause characteristics over the Indian region have been studied using radio occultation measurements (CHAMP) on the basis of cold point criterion. Tropopause height shows large variation in the latitude range $\sim 30^{\circ}-40^{\circ} \mathrm{N}$ during winter. Tropopause temperature less than $-82^{\circ} \mathrm{C}$, assumed to facilitate troposphere to stratosphere air transport, is observed at a number of tropical Indian locations and no seasonal pattern is observed in its occurrence. The bias in temperature and refractivity deduced from radiosonde and radio occultation measurements is also presented.

\section{Introduction}

Troposphere is the lowest portion of earth's atmosphere and hold approximately $80 \%$ of atmospheric airmass. The radio wave propagation through troposphere depends on refractive index of the medium. The refractive index of the medium depends on atmospheric pressure, temperature and humidity. The properties of radio wave make it an efficient tool to study the atmosphere. Earlier, atmospheric monitoring was based on radiosonde measurements. The availability of global positioning system (GPS) signals has given a new technique for studying the atmosphere. The GPS satellites orbiting around $20,000 \mathrm{~km}$ above the surface of the earth continuously emits radio signals. The GPS signals received on low earth orbiting satellite
(LEO) is getting occulted by atmosphere as GPS satellite rises above or sets behind the horizon of the earth. Atmosphere causes refraction of radio signals as it passes through it. This time delay and bending is the basis of estimation of atmospheric refractivity and temperature (Wickert et al 2001). Radio occultation technique is free of interference from cloud, aerosol, precipitation and it provides global coverage. Radio occultation measurements combined with radiosonde measurements give a better picture of atmospheric activities.

There were some comparison studies of radio occultation observations with radiosonde observations and meteorological analyses from weather models. Kurisinky et al (1997) reported mean bias of $0.5^{\circ} \mathrm{C}$ between radio occultation and Europeon Centre for Medium Range Weather

Keywords. Cold point tropopause; cold tropopause; tropospheric stratospheric exchange; radio occultation, subtropics; atmospheric sciences; climate; upper atmosphere. 
Forecasts (ECMWF) weather analyses over northern hemisphere. Wickert et al (2004) reported radio occultation observations show a mean temperature bias of less than $0.4^{\circ} \mathrm{C}$ between meteorological analyses from ECMWF in the altitude range $10-25 \mathrm{~km}$ based on comparison studies performed during the period from March 2002 to December 2002. They confirmed the results with global radiosonde network. About $69 \%$ of the radiosonde observations used for comparison studies are in the range $30-70^{\circ} \mathrm{N}$. In tropical region, temperature bias in relation to analyses is found to be larger than that with radiosonde observations. A temperature bias of less than $1.5^{\circ} \mathrm{C}$ in the pressure range $300-10 \mathrm{mb}$ (Schmidt et al 2005 ) is reported between radio occultation and radiosonde observations. These results are based on the observations between May 2001 and December 2004. The comparison of two CHAMP temperature profiles over Sepang $\left(2.71^{\circ} \mathrm{N}, 101.7^{\circ} \mathrm{E}\right)$ and Singapore $\left(1.36^{\circ} \mathrm{N}, 103.98^{\circ} \mathrm{E}\right)$ with radiosonde and analyses from National Centers for Environmental Prediction (NCEP) showed excellent agreement over all heights below tropopause (Kishore et al 2006). Only very few comparative studies of radio occultaton and radiosonde observations were reported over the Indian region. Kuo et al (2005) made comparison of vertical refractivity profiles from radio occultation measurements with the radiosonde observations during the period from June 2001 to March 2004 over India, China, Japan, Australia and Russia.

The radio refractivity data is required for design of tropospheric communication circuits and radar operations as well as remote sensing applications, which are widely used in defense and aviation sector. Temperature observations are needed in weather forecasts and global climate change related studies. The global coverage of occultation measurements makes it useful in the areas where radiosonde observations are limited, particularly in oceanic regions.

Tropopause is the boundary between turbulent troposphere and more stable stratosphere and plays a significant role in stratospheric tropospheric exchange. Tropopause affects the transport of ozone, water vapour and aerosol between troposphere and stratosphere and has an important role in many dynamic weather changes in troposphere like cyclones and jet streams. Coupling between troposphere and stratosphere by dynamical, chemical and radiative processes has an effect on climate variability and global change. It is found that wave-induced forces withdraw air upward from troposphere in tropics and pushes through lower stratosphere towards poles and pushes it downwards in extra tropics (Holton et al 1995). Different definitions exist for tropopause, based on criteria like variation in temperature lapse rate, potential vorticity, minimum temperature and ozone gradient. Convective activities occurring in the troposphere have strong influence on tropical tropopause region. Convective processes are found to correlate better with minimum temperature or cold point tropopause (CPT) than other definitions of tropopause (Schmidt et al 2005). In studies related to tropospheric stratospheric exchange CPT definition is preferred. Tropical tropopause is colder and extremely drier than at higher latitudes (Jain et al 2006).

The tropopause structure has strong influence on tropospheric stratospheric exchange. It is considered that air enters from troposphere to stratosphere primarily through tropics. According to fountain hypothesis, tropospheric air enters stratosphere through areas where tropopause temperature is less than their mean longitudinal values to freeze dry air entering stratosphere (Zhou et al 2001). Stratospheric water vapour concentration is influenced by tropopause structure although exact relation between them is not clear (Schmidt et al 2005). Considering water vapour concentration in stratosphere, it is estimated that troposphere to stratosphere transport occurs through areas where temperature is less than $-82^{\circ} \mathrm{C}$ (Zhou et al 2001). By studying temperature distribution, it is assumed that during winter season tropospheric air enters through Indonesian region (Newel and Gould 1981). It is found in some studies tropopause temperature as low as $-82^{\circ} \mathrm{C}$ occurs in tropical Indian region during summer monsoon and post-monsoon months (Jain et al 2006). The occurrence of low tropopause temperature is found to be mostly in oceanic region compared to land (Jain et al 2006). The knowledge of tropopause structure and its variability are important in understanding processes involved in climate variability. On large time scales tropopause variation gives information about general circulation processes (Angell and Korshover 1974). In shorter scales phenomena like tropopause folds believed to play an important role in exchange of chemical species and vorticity.

The tropopause height is sensitive to temperature changes in the troposphere and stratosphere caused by both natural and human factors. Thus, the height of the tropopause provides another fingerprint of human effects on climate. It is lower at higher latitudes and higher at lower latitudes. In tropics it is above $16 \mathrm{~km}$ and in extra tropics it is between 8 and $12 \mathrm{~km}$. The tropopause height variation is also one of the mechanisms through which the tropospheric-stratospheric exchange process can be understood. The stratospheric water vapour concentration is found to be increased in recent years. The source of water vapour in stratosphere 
is from methane oxidation and transport from tropical troposphere. One possible mechanism for such increase through transport from tropical troposphere could be the temporal increase in tropical tropopause temperature or tropopause height, which could allow large saturation mixing ratios to enter stratosphere (Randel et al 2000).

The subtropics are the region of transition between tropics and extra tropics characterized by split in tropopause. Atmospheric phenomena like tropopause fold and subtropical jet stream occurs in this region. Jet streams are fast flowing narrow currents occurring in the atmosphere near tropopause. Stratospheric intrusion of air into the baroclinic zone beneath upper tropospheric jet stream is known as tropopause fold. Tropopause folds are a mechanism of stratospheric tropospheric exchange in which dry stratospheric air rich in ozone transported downwards to tropospheric levels and tropopause height drops suddenly as the stratospheric air replaced in fold is warmer than tropospheric air. Double tropopauses (lapse rate criteria) are found to occur frequently in this region during winter months associated with cyclonic circulation systems (Randel et al 2007). This may be due to above jet streams stability of lower stratosphere is reduced giving rise to poleward transport of upper tropospheric air. The actual mechanism behind the transport is not clear and it does not have any relation with the occurrence of storm tracks or Rossby wave breaking at tropopause, which occurs in summer season (Randel et al 2007). Extra tropics are characterized by large dynamic variability characterized by complex spatial structure.

The results on radio refractivity and temperature profile over two Indian tropical stations, Kolkata $\left(22.65^{\circ} \mathrm{N}, 88.15^{\circ} \mathrm{E}\right)$ and New Delhi $\left(28.58^{\circ} \mathrm{N}, 77.20^{\circ} \mathrm{E}\right)$ deduced from radiosonde and radio occultation measurements are presented in this paper. The tropopause characteristics over Indian region have also been studied using radio occultation (RO) observations.

\section{Database}

The radiosonde observations were obtained from British Atmospheric Data Center (BADC) and GPS/CHAMP (Challenging Mini Pay Load) radio occultation observations (GeoForschungsZentrum (GFZ), Potsdam, Germany) obtained through Information System Data Centre (ISDC) (http://isdc.gfz-potsdam.de/champ). The CHAMP/GPS satellite was launched on July 15, 2000 into an almost circular and near polar orbit (with the inclination of $87^{\circ}$ ) with an initial altitude of $454 \mathrm{~km}$. Black Jack GPS receiver developed by Jet Propulsion Laboratory capable of tracking GPS L2 (frequency, L2 1.277 GHz) signals modulated with Y code is used (Kuo et al 2004). The CHAMP mission provides observations at a vertical resolution of $\sim 200 \mathrm{~m}$ at an average of $\sim 260$ atmospheric profiles per day. The occultation data processing system uses occultation data by CHAMP, ground tracking data of GPS satellites and precise orbit information of satellites. The phase observations made by CHAMP are synchronized with observations of reference ground network stations. Atmospheric bending angle is calculated from measured time series of phase path increase of two GPS frequencies (L1 $\sim 1.575 \mathrm{GHz}, \mathrm{L} 2)$ and of satellite velocities and positions. Atmospheric refractivity is derived from bending angles using Abel inversion. In dry conditions atmospheric pressure and temperature are deduced from refractivity using hydrostatic equation. In wet conditions, additional background information is utilized for deriving temperature. Radiosonde measurements are taken twice a day at 00:00 and 12:00 (UTC) pertaining to early morning and late evening Indian local time. IM-MK3 radiosonde is used for measurement (Kuo et al 2005). White painted rod thermistor is used for sensing temperature.

\section{Comparison of CHAMP and radiosonde measurements}

The comparison of CHAMP observations with radiosonde measurements is performed to examine the reliability of using both together for various applications. The radio refractivity and temperature observations at different altitude levels are provided directly by CHAMP. But, in case of radiosonde, radio refractivity is estimated from pressure, temperature and dew point temperature by using following relations.

Refractivity $N$ is calculated using expression (1):

$$
N=(77.6 P / T)+\left(3.73 \times 10^{5} e / T^{2}\right),
$$

where $P$ is pressure in mb, $T$ is temperature in Kelvin, $e$ is vapour pressure in mb.

Vapour pressure is calculated from dew point temperature using expression (2):

$$
e=e s_{0} \times \exp \left(\frac{l v}{R v} \times\left(\frac{1}{T_{0}}-\frac{1}{T_{d}}\right)\right)
$$

where $e s_{0}$ is the reference saturation vapour pressure at $\mathrm{STP}=6.11 \mathrm{mb} ; T_{0}$ is the reference 

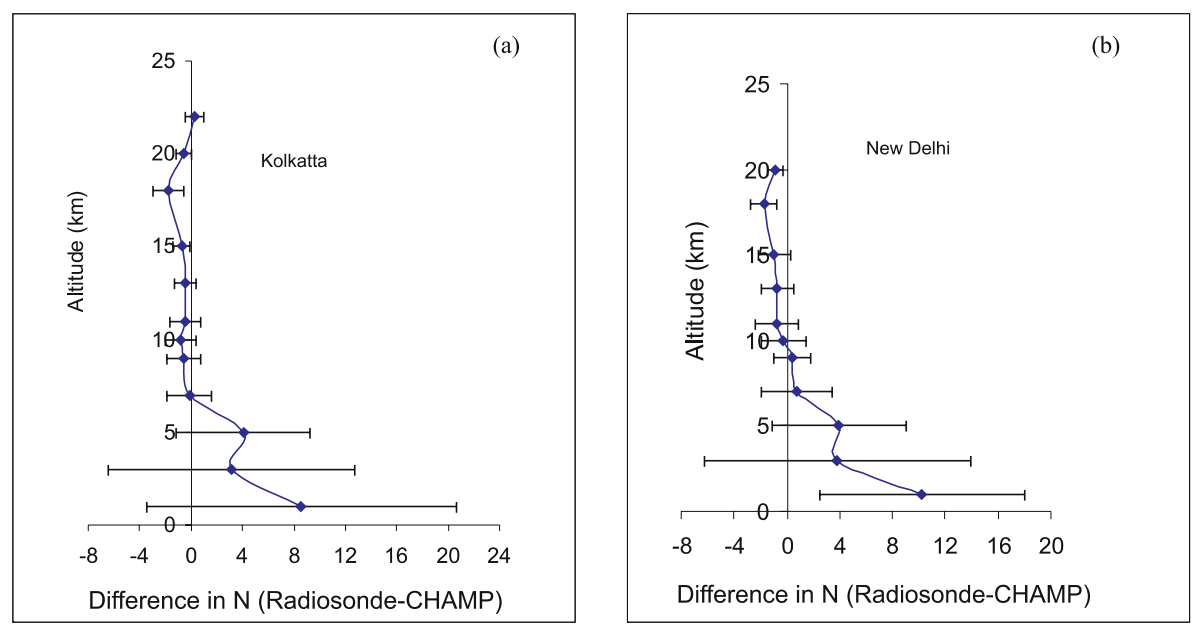

Figure 1. Profile of the mean value of the difference in refractivities between radiosonde and CHAMP data at (a) Kolkata and (b) New Delhi stations. (Horizontal bars indicate the standard deviation of the data.)

temperature at $\mathrm{STP}=273.15 \mathrm{~K} ; T_{d}$ is dew point temperature $(\mathrm{K}) ; T$ is temperature $(\mathrm{K}) ; l v$ is latent heat of vapourization of water $=2.5 \times 10^{6}$ joules per kilogram; and $R v$ is gas constant for water vapour (461.5 joules Kelvin/kilogram).

The results on radio refractivity and temperature deduced from the radiosonde measurements over Kolkata and New Delhi have been compared with CHAMP observations at different altitude levels. The comparison is performed with the criteria that both measurements are with in the range of two degrees of position and time difference between measurements is less than 5 hours. The analysis is done for the period from 2002 January 1 to 2006 December 31. The CHAMP profiles in the range (lat. $20^{\circ}-24^{\circ} \mathrm{N}$, long. $86^{\circ}-90^{\circ} \mathrm{E}$ ) are considered for Kolkata and in the range (lat. $27^{\circ}-31^{\circ} \mathrm{N}$, long. $75^{\circ}-79^{\circ} \mathrm{E}$ ) for New Delhi.

\section{Tropopause structure measurement}

The tropopause height and temperature is deduced for the latitude range $2^{\circ}-40^{\circ}$ and longitude range $65^{\circ}-100^{\circ}$ for the time period of 2002 to 2006 from radio occultation observations. The tropopause is detected using cold point criterion. The spatial and temporal coverage of occultation measurements are different for different years. This is overcome by estimating annual average of tropopause height and temperature at one degree spatial interval for the latitude and longitude range mentioned above.

\section{Comparison of vertical atmospheric profiles}

A total of 23 profiles obtained for Kolkata and 31 profiles over New Delhi have been utilized for comparison purpose. In lower atmospheric layers below $4 \mathrm{~km}$ radio occultation measurements provide only few observations. The radio refractivity measurements show large variations below $5 \mathrm{~km}$. The mean value of difference in refractivity between CHAMP and radiosonde measurements (CHAMP-radiosonde) is deduced for different altitudes and plotted against altitude. The results of radio refractivity are shown in figure 1 . The horizontal bars indicate standard deviation of radio refractivity. The difference in refractivity between both modes of measurements is large below $5 \mathrm{~km}$ altitude and above $5 \mathrm{~km}$, the difference in refractivity between two modes of measurements is less than $2 N$. The variation between the results on radio refractivity from radiosonde and radio occultation in lower troposphere may be due to the large scale variation of water vapour content in the Indian region. The humidity in lower troposphere over tropics is significant.

The temperature measurements also show large variation between radio occultation and radiosonde observations below $5 \mathrm{~km}$ altitude. Figure 2 shows the comparison of typical temperature and refractivity profiles observed on a particular day. Above $5 \mathrm{~km}$ altitude, bias between measurements decreases and above $10 \mathrm{~km}$ altitude bias reduces considerably. In the altitude range from $10 \mathrm{~km}$ to tropopause altitude, the mean value of bias between the measurements is less than $2.5^{\circ} \mathrm{C}$. The radio refractivity derived from GPS occultation measurement is composed of dry and wet contribution. In deriving temperature and pressure from refractivity profiles, information about water vapour is required (Kurisinky et al 1997). The required background information of humidity is taken from operational meteorological analysis of European Centre for Medium-Range Weather 

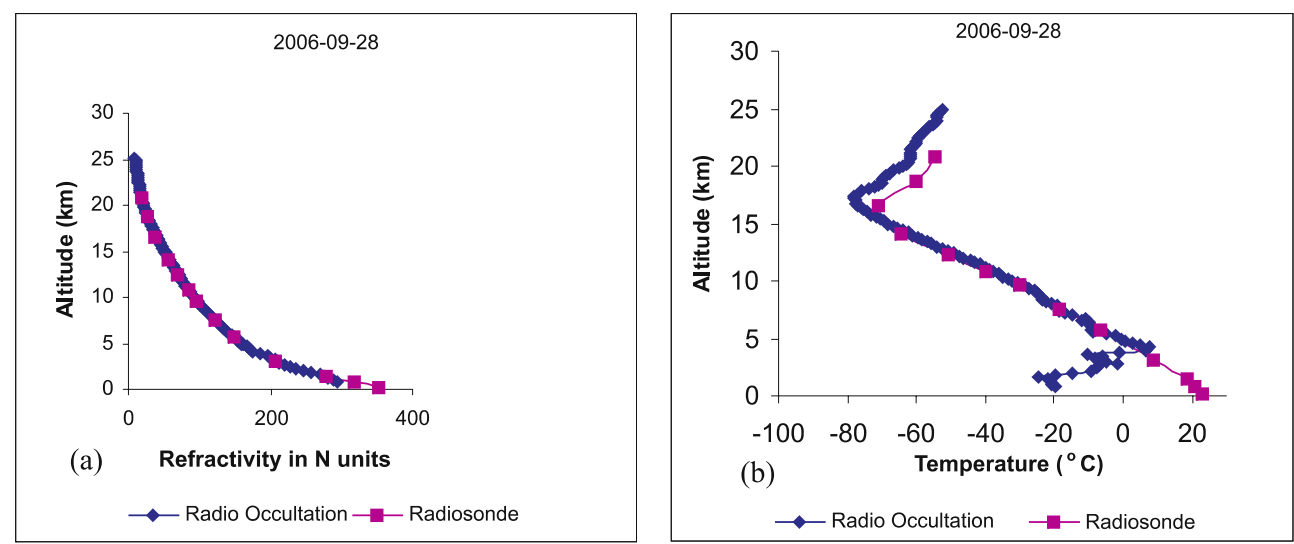

Figure 2. Typical vertical profile of (a) refractivity and (b) temperature obtained with CHAMP and radiosonde observations at New Delhi observed on a particular day.

Forecasts (ECMWF) (Wickert et al 2004). Dry atmosphere and hydrostatic equilibrium is assumed above $10-12 \mathrm{~km}$ in deducing atmospheric parameters from bending angle (Narayana Rao et al 2007). These assumptions may not be strictly valid during strong convections and presence of water vapour in upper troposphere. In tropical tropopause region strong convections and cirrus clouds are reported to occur frequently (Sunil Kumar et al 2003; Narayana Rao et al 2007). It is reported in tropical upper troposphere, ECMWF analyses differ from real atmospheric situations (Wickert et al 2004). The comparison studies temperature measurements of different type of radiosondes with radio occultation observations reported different responses (Kuo et al 2005). The accuracy of radiosonde measurements depends on the temperature sensor error and error in height (pressure) measurements. Solar heating produces significant errors in temperature measurements below $100 \mathrm{mb}$ pressure levels and in cloudy conditions.

\section{Tropopause height}

The results on tropopause height are based on 2729 occultation profiles during the period. The tropopause height is found to vary between 9 and $23 \mathrm{~km}$ and temperature between $-57^{\circ}$ and $-96^{\circ} \mathrm{C}$. The mean value of tropopause height is found to be $17.3 \mathrm{~km}$ that is well in the range of earlier observations (Venkat Ratnam et al 2005). In $90 \%$ of the observations tropopause height is in the range of $16-19 \mathrm{~km}$. The histogram of the tropopause height with latitude is given in figure 3. The high tropopause height characteristic of tropical region is found to exist up to $40^{\circ} \mathrm{N}$. There are many studies suggesting the widening of tropical region towards poles as a result of jet

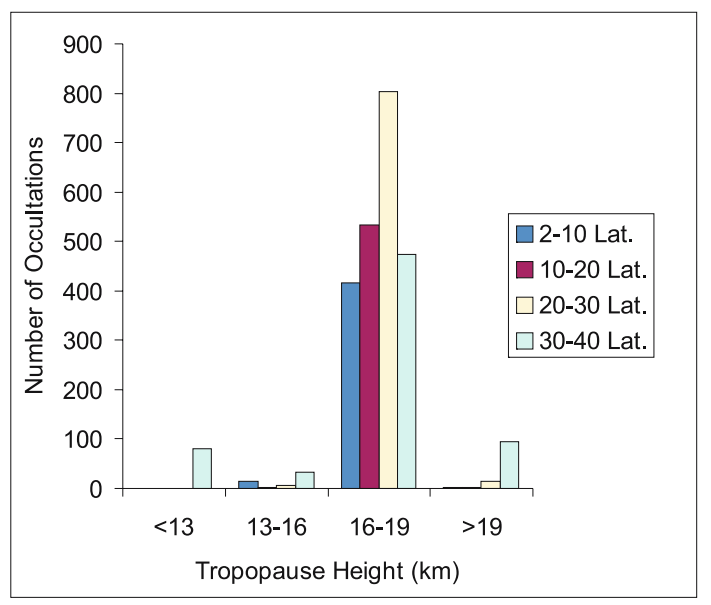

Figure 3. Histogram analysis of tropopause height for different latitude ranges.

streams, circulation systems and anthropogenic activities (Fu et al 2006; Hudson et al 2006). The expansion of tropical tropopause around $5^{\circ}$ to $8^{\circ}$ towards poles is reported in the radiosonde studies conducted in the period of 1979-2005 (Seidel and Randel 2007). The tropopause height in the tropical region is found to be within $15-20 \mathrm{~km}$. The contour maps showing geographical variation of tropopause height and tropopause temperature are shown in figures 4 and 5 respectively.

It is seen that tropopause height shows small variations meridionally and zonally in the latitude range $2^{\circ}-30^{\circ} \mathrm{N}$. But, in the range of $30^{\circ}-40^{\circ} \mathrm{N}$ latitude large variation in tropopause height occur zonally. The tropopause temperature is found to increase with latitude and higher tropopause temperature is observed in the latitude range of $30^{\circ}-40^{\circ} \mathrm{N}$. Figure 6 shows the meridional variation of tropopause temperature in this period. It is also reported earlier that tropopause temperature increases with latitude (Kishore et al 2006). 


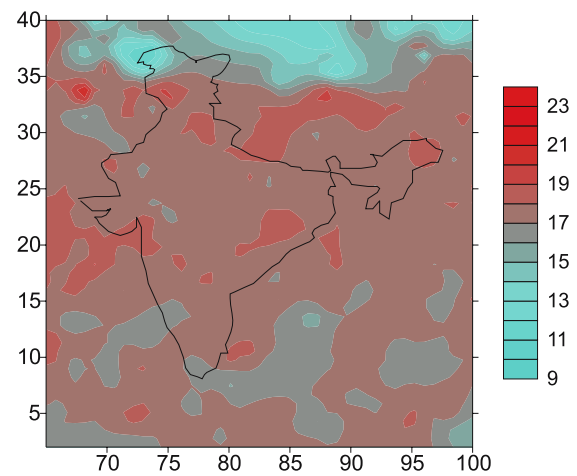

(a) 2002

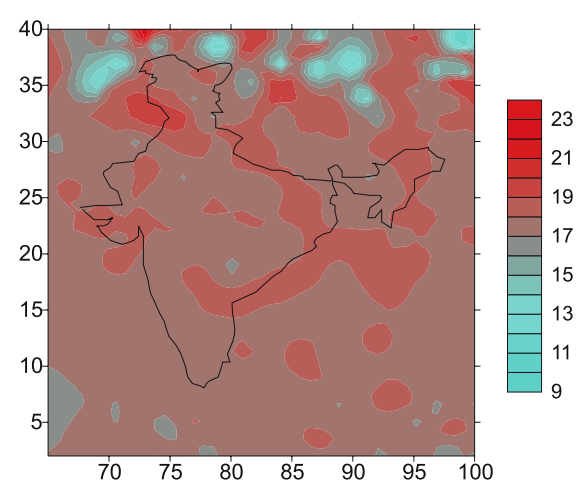

(c) 2004

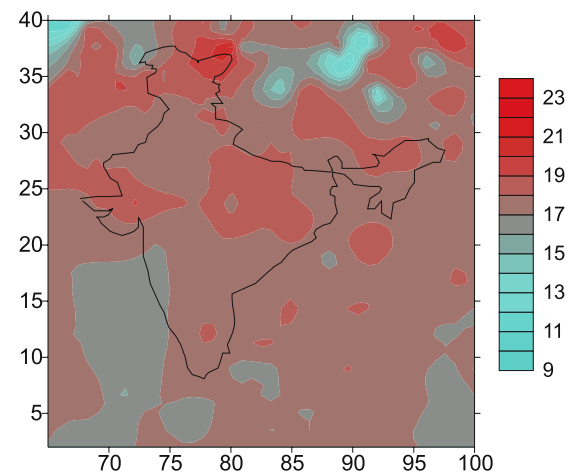

(b) 2003

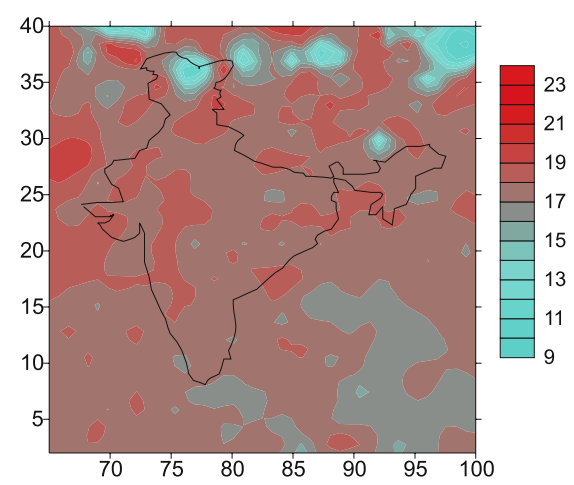

(d) 2005

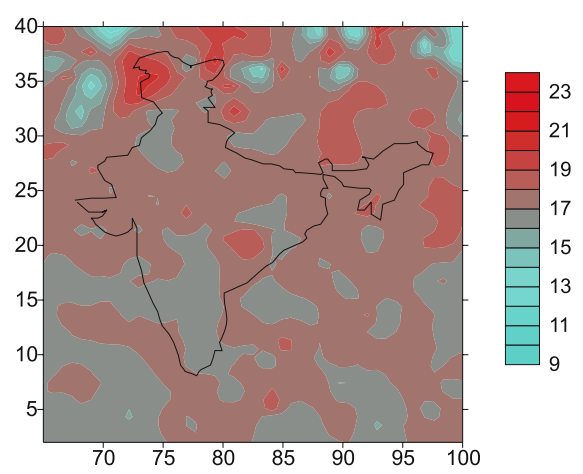

(e) 2006

Figure 4. Geographical variation of tropopause height in $(\mathrm{km})$ for different years.

\section{Cold tropopause temperature}

Out of all observations pertaining to the period from 2002 to 2006 tropopause temperature less than $-82^{\circ} \mathrm{C}$ (cold tropopause temperature) is observed on $24 \%$ of time. Figure 7 shows yearwise distribution of cold tropopause temperature along with observation points. The cold tropopause temperature is not obtained beyond $32^{\circ} \mathrm{N}$. In the year 2002, the number of cold tropopauses obtained above $23.5^{\circ} \mathrm{N}$ latitude is more than that in other years. Considering tropical region alone, cold tropopause was obtained for $44 \%$ of the cases, while in 2006, in tropical region cold tropopause was obtained only in $30 \%$ of the cases. The tropopause height corresponding to cold tropopause varies between 16 and $19.6 \mathrm{~km}$. The present observations confirm the previous studies made in the region using radiosonde measurements during monsoon and post-monsoon months about the existence of cold tropopauses (Jain et al 2006). No seasonal or diurnal bias is observed in the occurrence of these low tropopause temperatures. There were studies, which also reported mean monthly tropopause temperature less than $-82^{\circ} \mathrm{C}$ in the tropical Pacific region during the months November to April 


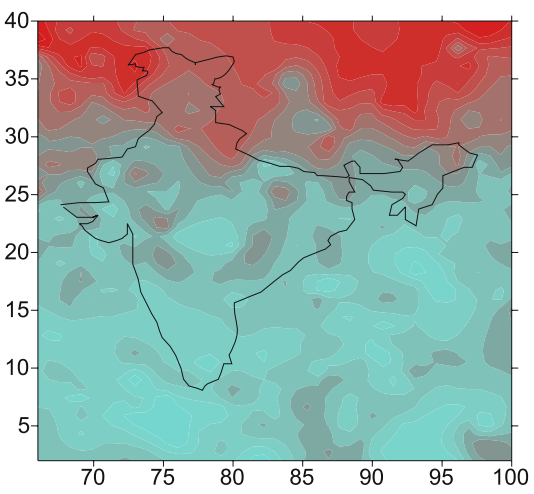

(a) 2002

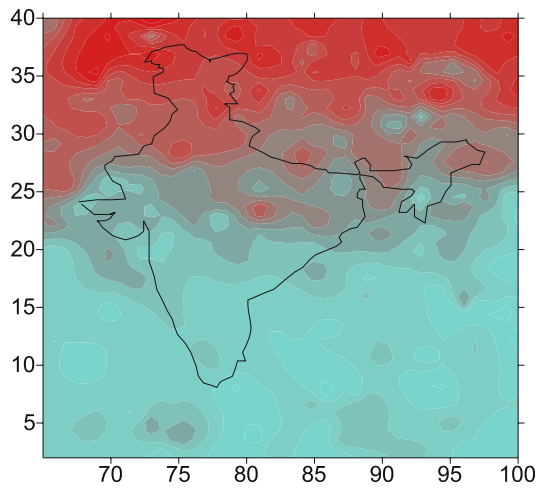

(c) 2004
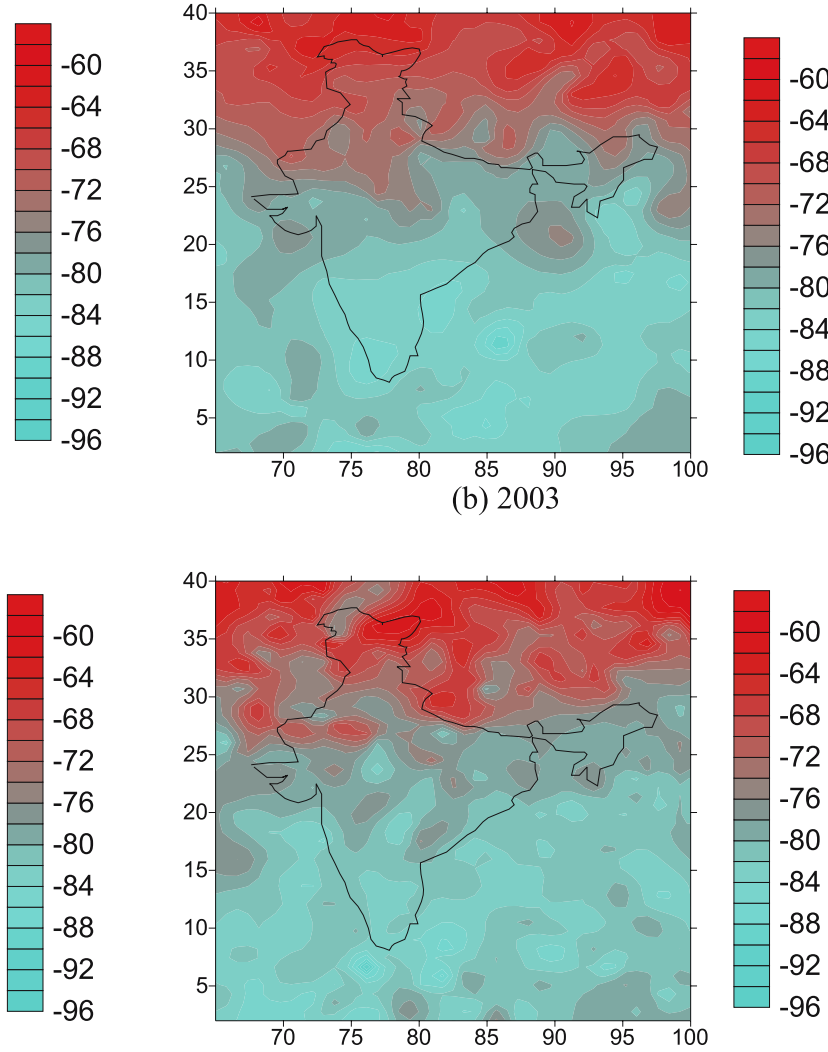

(d) 2005

(b) 2003
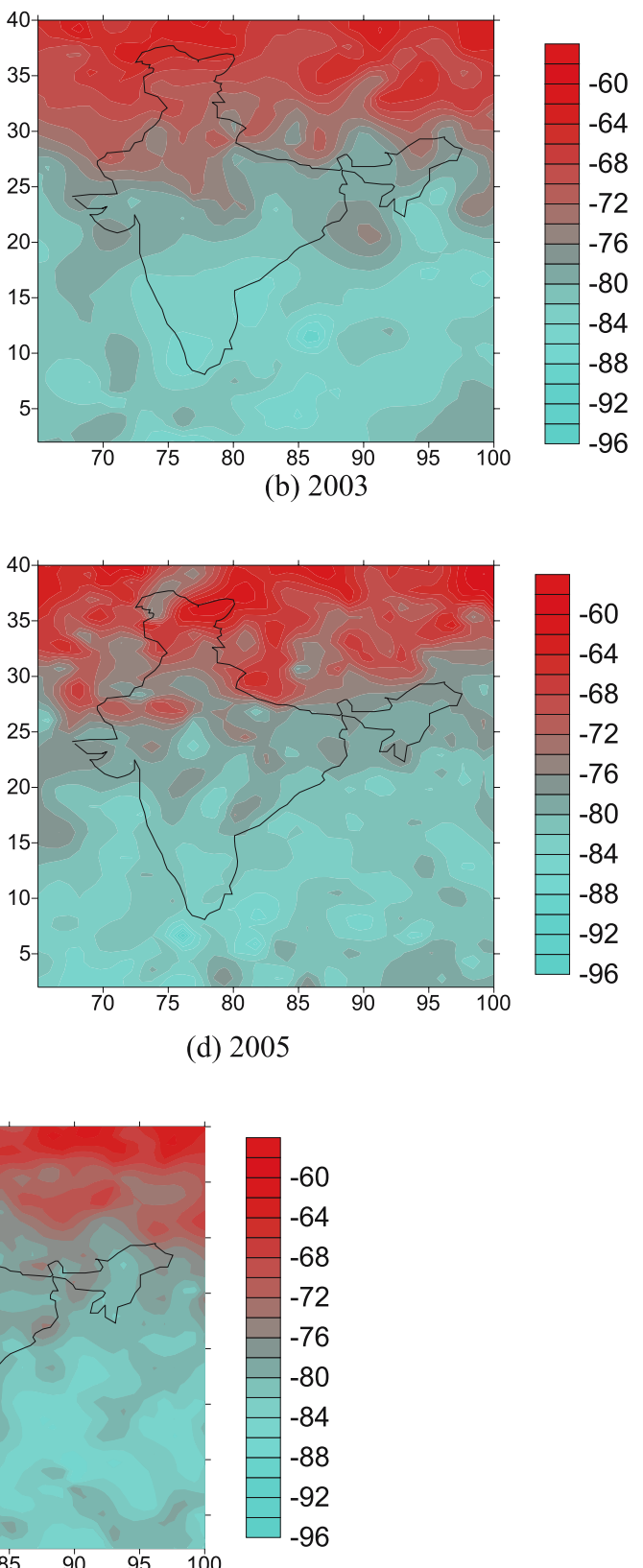

(e) 2006

Figure 5. Geographical variation of tropopause temperature in $\left({ }^{\circ} \mathrm{C}\right)$ for different years.

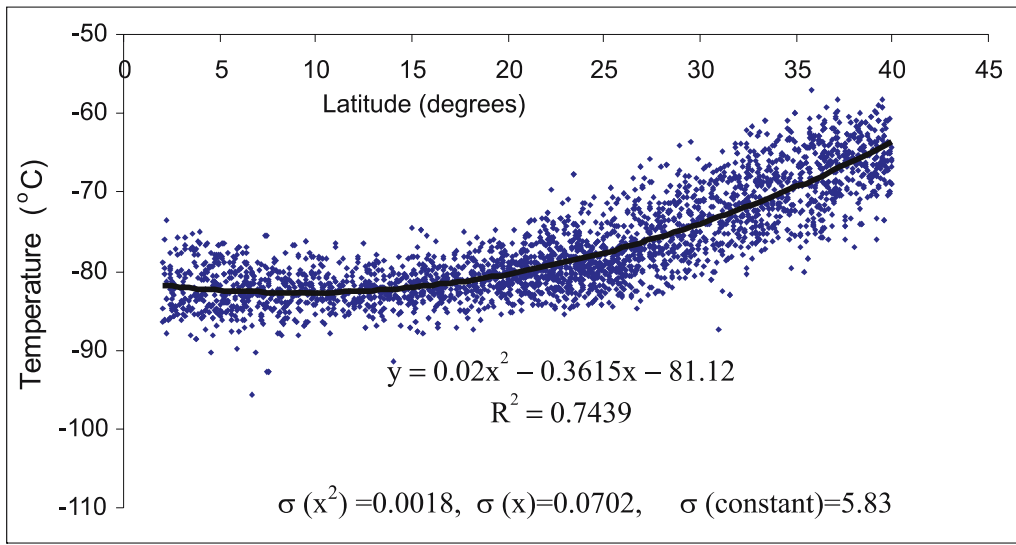

Figure 6. Meridional variation of tropopause temperature. 


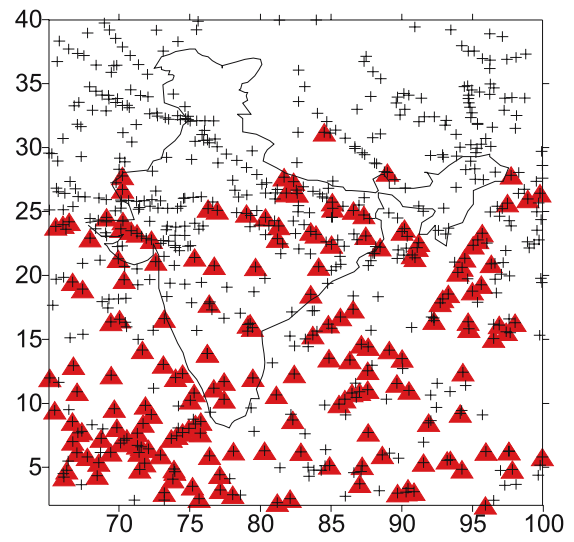

(a) 2002

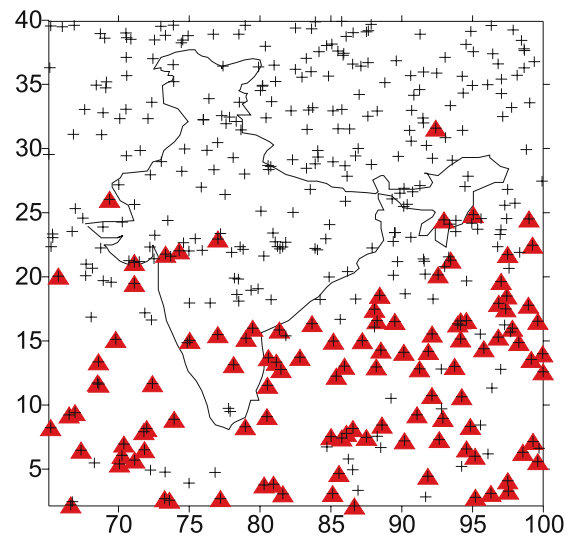

(c) 2004

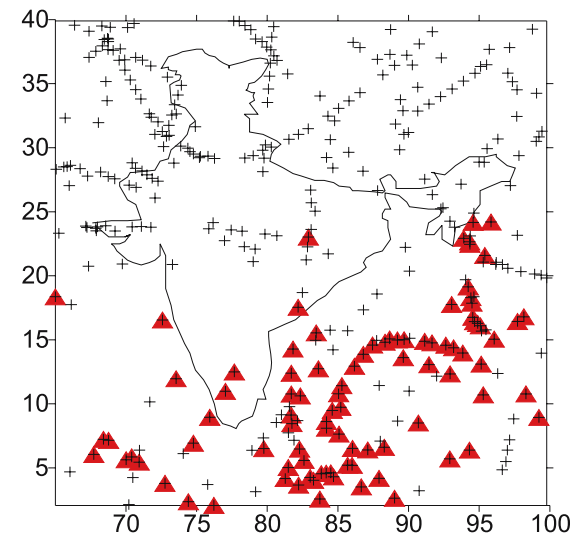

(b) 2003

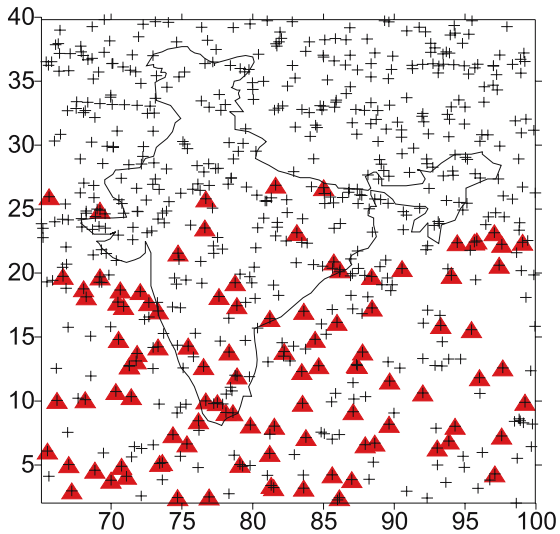

(d) 2005

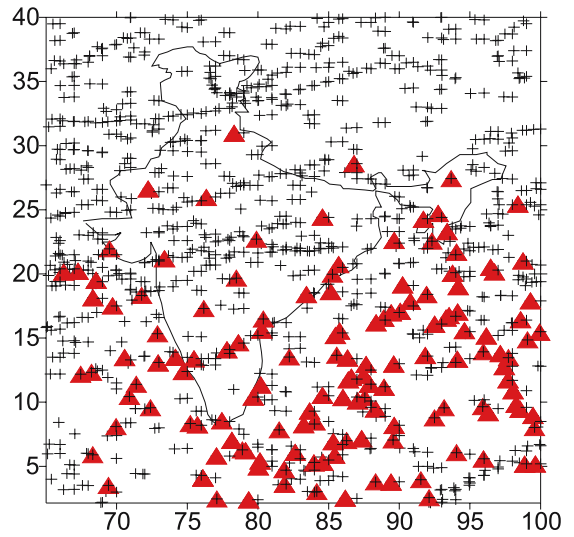

(e) 2006

Figure 7. Yearwise distribution of cold tropopause. $\boldsymbol{\Delta}$ represents observation sites where temperature is less than $-82^{\circ} \mathrm{C}$. + represents observation sites.

(Reid and Gage 1996). Monthly occurrences of cold tropopause for different years are given in table 1. These observations are not in agreement with observations of Jain et al (2006); of occurrences of cold tropopause more near to midnight hours and in oceanic region than coastal stations. The tropical upper troposphere is found to be influenced by convective activities occurring in the region and wave forcing in the extra tropics (Reid and Gage
1996). It is reported that cold point temperature depends on the concentration of ozone, carbon dioxide and water vapour in the upper troposphere (Thuburn and Craig 2002).

\section{Tropopause in subtropics}

It is found that the tropopause shows large variations in the latitude range $30^{\circ}-40^{\circ} \mathrm{N}$. In this 
Table 1. Monthly distribution of tropopause temperature less than $-82^{\circ} \mathrm{C}$ for different years.

\begin{tabular}{lccccc}
\hline & \multicolumn{5}{c}{ Number of occurrences of tropopause temperature less than $-82^{\circ} \mathrm{C}$} \\
\cline { 2 - 6 } Month & 2002 & 2003 & 2004 & 2005 & 2006 \\
\hline January & 17 & 12 & 18 & 14 & - \\
February & 9 & 12 & 15 & 29 & 13 \\
March & 23 & 5 & 25 & 13 & 30 \\
April & 15 & 19 & 18 & 14 & 13 \\
May & 28 & 19 & 1 & 3 & 38 \\
June & 4 & 6 & - & - & 9 \\
July & 24 & - & - & 9 & - \\
August & 11 & Data not available & - & 6 & 2 \\
September & 6 & Data not available & - & 2 & 5 \\
October & 8 & Data not available & - & 5 & 1 \\
November & 26 & Data not available & 3 & 5 & 9 \\
December & 17 & Data not available & 31 & 7 & 21 \\
\hline
\end{tabular}
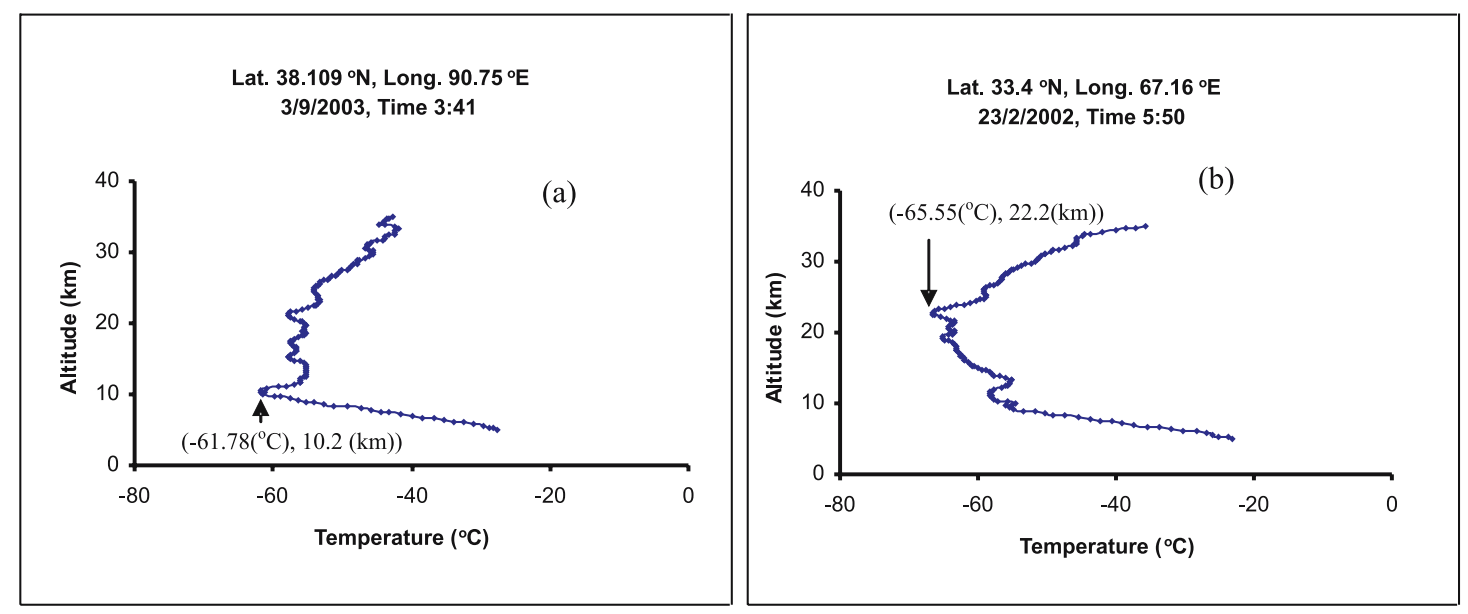

Figure 8. Temperature profiles showing tropopause height and tropopause temperature.

latitude range tropopause height varies from 9 to $23 \mathrm{~km}$. Figure 8 shows some characteristic temperature profiles with tropopause height variation. It is reported on the basis of radiosonde observations in subtropical region that tropopause exhibits bimodal distribution having the characteristics of both tropics and polar region (Seidel and Randel 2007). Tropopause height above $20 \mathrm{~km}$ is obtained in $5 \%$ of observations made in the latitude range $30^{\circ}-40^{\circ} \mathrm{N}$. The tropopause heights above $20 \mathrm{~km}$ have been reported in some other studies based on lapse rate criteria (Randel et al 2007). The distribution of tropopause height with latitude is shown in figure 9 . This extremely high tropopause is observed in the months from November to April coinciding with winter months. The tropopause heights below $13 \mathrm{~km}$ are also observed in winter months. There is no longitudinal bias obtained in these observations. The tropopause temperature corresponds to extremely high and low tropopause height, comes in the range from $-57^{\circ}$ to $-73^{\circ} \mathrm{C}$. As air parcels are pulled upwards adiabatic, cooling produces temperature below their radiative values and tropopause height increases. While air parcels are pushed downward adiabatic heating produces temperature above their radiative values resulting in lower tropopause heights (Holton et al 1995). So these extremely high and low tropopause heights can be considered as an evidence for exchange of airmass between troposphere and stratosphere in this region. The wave induced forces are assumed to exert non-local control over tropospheric stratospheric exchange in extra tropics. The strongest, wave induced forces are occurring in the northern hemisphere during winter season (Holton et al 1995). It is reported on the basis of ozone observations that multiple tropopauses observed in this region is associated with deep cyclonic circulation systems of tropical tropospheric air above subtropical jet stream 

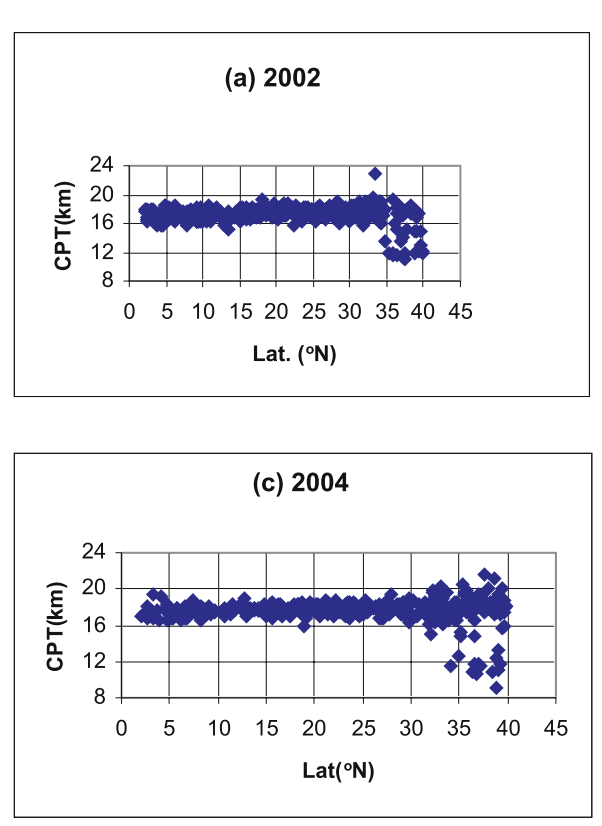

(b) 2003

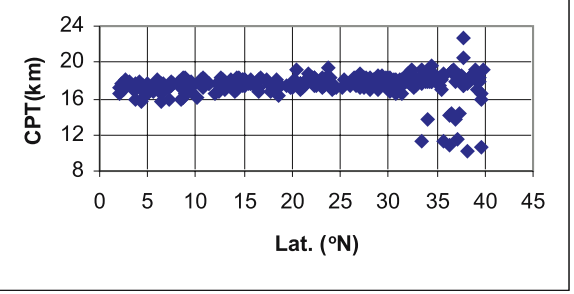

(d) 2005

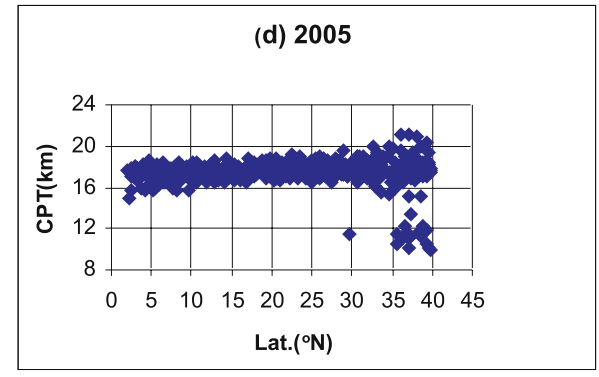

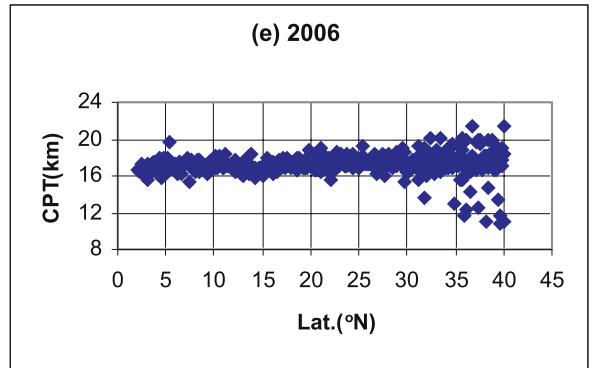

Figure 9. Variation of tropopause height with latitude for different years.

reaching up to lower stratosphere. Extremely high tropopause may be due to some cyclonic circulation systems and transport of tropospheric air into stratosphere as observed in the case of multiple tropopauses. Extremely low tropopause height may be associated with tropopause folds occurring with jet streams and transport of stratospheric air into troposphere. But the occurrence of tropopause fold does not show any seasonality. In our observations, extremely low tropopause heights have been observed only in the winter season. During Rossby wave breaking events near tropopause, stratospheric air enters in the troposphere and tropospheric air enters in stratosphere (Gregory Postel and Mathew Hitchman 2001). These events, also reported in summer months are not coinciding with present observations (Randel et al 2007). Further investigation is required to find out exact mechanism behind these atmospheric observations.

\section{Conclusion}

In the present study, some characteristics of tropopause structure parameters and comparative study of radiosonde and $\mathrm{RO}$ observations over the Indian region have been presented. The utility of RO techniques to study tropospheric climatology is examined. But it is found that in lower troposphere and beyond tropopause region radiosonde observations and RO observations do not agree. In studying weather parameters in the lower troposphere of the region using radio occultation techniques, water vapour climatology suiting to the region and the improved data retrieval techniques are required.

Existence of cold tropopauses indicates that tropical Indian region acts as a source of troposphere to stratosphere transport of airmass. There were studies which suggested that contribution of tropical Indian region to tropospheric to stratospheric transport in monsoon and post monsoon months (Jain et al 2006). But present study indicates this transport does not have any seasonal dependency. The large variation of tropopause height in subtropical region suggests the possibility of two-way tropospheric stratospheric exchange of airmass occurring in the region during winter time. The actual mechanism behind such transport has to be studied in detail. In tropical region 
tropopause height varies between 15 and $20 \mathrm{~km}$. The existence of high tropopause heights at higher latitudes suggests that the expansion of tropical region is more than that reported by earlier investigators.

\section{Acknowledgements}

We wish to thank Information System Data Centre (ISDC) and British Atmospheric Data Centre (BADC) for providing CHAMP and radiosonde data respectively. One of the authors (JCJ) is thankful to CSIR for providing fellowship to carry out the research work.

\section{References}

Angell J K and Korshover J 1974 Quassi-biennial oscillation and long-term fluctuations in tropopause pressure and temperature and the relation to stratospheric water vapour; Mon. Weather Rev. 102 29-34.

Fu Q, Johanson C M, Wallace J M and Reichler T 2006 Enhanced mid-latitude tropospheric warming in satellite measurements; Science 3121179.

Gregory A Postel and Mathew H Hitchman 2001 A case study of Rossby wave breaking along subtropical tropopause; Mon. Weather Rev. 129 2555-2569.

Holton J R, Haynes P H, McIntyre M E, Douglass A R, Rood R B and Pfister L 1995 Stratosphere-troposphere exchange; Rev. Geophys. 33 403-439.

Hudson R D, Andrade M F, Follette M B and Frolov A D 2006 The total ozone field separated into meteorological regimes - Part II: Northern Hemisphere mid-latitude total ozone trends; Atmos. Chem. Phys. 6 5183-5191.

Jain A R, Siddarth Shankar Das, Tuhin K Mandal and Mitra A P 2006 Observations of extremely low temperature over Indian tropical region during monsoon and post monsoon months: Possible implications; J. Geophys. Res. 111 D07106.

Kishore P, Namboothiri S P, Igarashi K, Jonathan H Jiang, Chi O Ao and Larry J Roamns 2006 Climatological characteristics of the tropical tropopause parameters derived from GPS/CHAMP and GPS/SAC-C satellite measurements; J. Geophys. Res. 111 D20, D20110, 10.1029/2005JD006827.

Kuo Y H, Wee T K, Sokolovskiy S, Rocken C, Schreiner W, Hunt D and Anthes R A 2004 Inversion and Error
Estimation of GPS Radio Occultation Data; J. Meteor. Soc. Japan 82(1B) 507-531.

Kuo Y H, Schreiner W S, Wang J, Rossiter D L and Zhang Y 2005 Comparison of GPS radio occultation sounding with radiosondes; Geophys. Res. Lett. 132 L 05817.

Kurisinky E R, Hajj G A, Schofield J T, Linfield R P and Hardy K R 1997 Observing earth's atmosphere with radio occultation measurement using the global positioning system; J. Geophys. Res. 102(D19) 23,429-23,465.

Narayana Rao D, Venkata Ratnam V, Krishna Murthy B V, Jagannadha Rao V V M, Sanjay Kumar Mehtha, Debashis Nath and Ghouse Basha S 2007 Identification of tropopause using bending angle profile from GPS radio occultation (RO): A radio tropopause; Geophys. Res. Lett. 34 L15809, doi: 10.1029/2007GL029709.

Newel R E and Gould Stewart S 1981 A stratospheric fountain?; J. Atmos. Sci. 38 2789-2796.

Randel W J, Wu F and Gaffen D J 2000 Interannual variability of the tropical tropopause derived from radiosonde data and NCEP reanalyses; J. Geophys. Res. 105(D12) $15,509-15,523$.

Randel W J, Seidel D J and Laura L Pan 2007 Observational characteristics of double tropopauses; J. Geophys. Res. 112 D07309.

Reid G C and Gage K S 1996 The tropical tropopause over the western Pacific: wave driving, convection and the annual cycle; J. Geophys. Res. 101(D16) 21,233-21,241.

Schmidt T, Heise S, Wickert J, Beyerle G and Reigber C 2005 GPS radio occultation with CHAMP and SACC: Global monitoring of thermal tropopause parameters; Atmos. Chem. Phys. 5 1473-1488.

Seidel D J and Randel W J 2007 Recent widening of tropical belt; J. Geophys. Res. 112 D20113.

Sunil Kumar S V, Parameswaran K and Krishna Murthy B V 2003 Lidar observation of cirrus clod near tropical tropopause: general features; Atmos. Res. 66 201-225.

Thuburn J and Craig G C 2002 On the temperature structure of the tropical substratosphere; J. Geophys. Res. 107(D2) 1029/2001JD000488.

Venkat Ratnam M, Tsuda T, Shiotani M and Fujiwara M 2005 New characteristics of tropical tropopause revealed by CHAMP/GPS measurements; SOLA 1 185-188.

Wickert J, Galas R, Beyerle G, Konig R and Reigber C 2001 GPS ground station data for CHAMP radio occultation measurements; Phys. Chem. Earth (A) 26 503-511.

Wickert J, Schmidt T, Beyerle G, Konig R, Reigber C and Jakowski N 2004 The radio occultation experiment aboard CHAMP operational data analysis and validation of vertical atmospheric profiles; J. Meteor. Soc. Japan 82(1B) 381-395.

Zhou X L, Marvin A Geller and Minghua Zhang 2001 Cooling trend of tropical tropopause temperature and its implications; J. Geophys. Res. 106(D2) 1511-1522. 